\title{
Developing intercultural and entrepreneurship competences among students - the case of business, IT, and services disciplines
}

\author{
Katarina Aškerc Zadravec ${ }^{1 *}$ \\ ${ }^{1}$ Ljubljana School of Business, Tržaška cesta 42, 1000 Ljubljana, Slovenia
}

\begin{abstract}
Developing intercultural and entrepreneurship competences provides future graduates with several benefits, wherein they are equipped for the globalized, intercultural world imbued with all of its uncertainties, diversities, and opportunities, both at the workplace and in everyday life. Entrepreneurial higher education institutions are characterized by an international and intercultural perspective - however, an institution cannot be entrepreneurial without being international, yet it can be international without being entrepreneurial. Entrepreneurial university provides a good environment, culture, and practices that enhance student entrepreneurship. Internationalisation, entrepreneurship, and in this context international entrepreneurship education are important topics to which academics and higher education institutions have increasingly devoted attention in recent years. This article discusses various aspects of developing intercultural and entrepreneurship competences, which are affected by different approaches to intercultural learning and teaching in the context of entrepreneurship education. In the last part of the paper, results are presented of quantitative research among Slovenian academics who teach business, IT, and services disciplines. Findings have shown that independent variables like teaching international students, providing distance learning with foreign institutions, inclusion of academics in training courses, and academics' international mobility all influence the frequency of using intercultural and entrepreneurial aspects in higher education learning and teaching practices.
\end{abstract}

\section{Introduction}

Higher education institutions are faced with diversified challenges in their future graduates' preparation to successfully work and live in a modern knowledge society, intertwined with an intercultural, entrepreneurial, and rapidly changing reality. International entrepreneurship education meets expectations of global citizenship in the 21st century, where personal responsibility for society's future welfare plays an important role.

With the comprehensive and systematic inclusion of intercultural, international, and entrepreneurial dimensions in formal and informal curriculum, study programmes (can) meet the needs of the modern knowledge society in general, and more precisely employer

\footnotetext{
* Corresponding author: katarina.askerc@,vspv.si
} 
expectations. In this context, Jones [1, p. 7] stresses the link between international experience and the development of employability skills, wherein many of the skills required by employers are those "which studies have found to be developed through international experience of study, work, volunteering, or service learning." Consequently, university curriculum should be better aligned to employers' needs, where graduates' intercultural and entrepreneurial skills hold an important role. Different approaches can be used to stimulate intercultural and entrepreneurial teaching and learning, but traditional lectures cannot lead to the implementation of this goal. Special attention should be paid to structural issues regarding the educational and curriculum design in order to promote entrepreneurship education in the internationalisation context [2].

In this paper, intercultural learning and teaching approaches are presented in connection with entrepreneurship education, beginning with the internationalisation of the home curriculum. Based on the survey among academics who teach business, IT, and services disciplines in Slovenian higher education, in the last part of the article key findings are presented on intercultural and entrepreneurial teaching practices, as well as on the articulation of these study programmes' learning outcomes in connection with intercultural and entrepreneurship education. According to the research question, findings have shown that independent variables like teaching international students, performing distance learning with foreign institutions, academics' inclusion in training courses, and their international mobility affect the frequency of using intercultural and also entrepreneurial aspects in higher education practices.

\subsection{Intercultural learning and teaching in the context of entrepreneurship education}

Entrepreneurial higher education institutions are characterized by an international and intercultural perspective, wherein an institution cannot be entrepreneurial without being international. However, an institution can be international without being entrepreneurial [3]. In this light, "entrepreneurial university (higher education institution) is a concept which explains institutions that provide a good environment, culture, opportunities, and practices that enhance student entrepreneurship" [4, p. 289]. Consequently, entrepreneurial higher education institutions support international activities (at home) and foster various forms of physically international activities, such as mobility procedures or (virtual) exchanges of students and staff (abroad).

Given that the percentage of mobile students remains low, the "purposeful integration of international and intercultural dimensions into the formal and informal curriculum for all students within domestic learning environments" [5, p. 69] seems to be an important way to provide international entrepreneurship education. Designing an innovative internationalised home curriculum is essential for its successful implementation, since strengthening the international and intercultural dimensions of teaching and learning activities is fundamentally valuable for entrepreneurship education [2].

\subsubsection{How to internationalise the entrepreneurship education?}

To educate students with a global entrepreneurship mindset is one of the most challenging issue in international entrepreneurship education. As highlighted by Smith and Paton [6], in order to internationalise the entrepreneurship education toolkit, learning environments need to include real-life cross-cultural experiences and activities. Authentic international student group work in line with experiential learning approaches and supported by modern technologies can offer more cost-effective routes to internationalising students' entrepreneurship experience [7]. Entrepreneurship education drives the development of 
innovative teaching formats, where greater international emphasis is needed to increase its attractiveness among domestic and international students (in domestic learning environment). Learning through social interaction, learning by doing, and applying experiential learning in project-based work etc. between domestic and international students are highly relevant approaches for fostering international elements of entrepreneurship courses [2].

Based on the case studies, the following approaches to teaching and learning activities for fostering the integration of entrepreneurship education courses in the context of internationalisation were identified by Matsekh-Ukrayinskyy, Schneider, Simons, Münch and Hoegsdal [2, p. 2]: (i) entrepreneurship courses value interdisciplinarity and are therefore great for fostering curriculum integration in the context of internationalisation; (ii) within internationalisation, a modular structure for ECTS integration is key in making the entrepreneurial course attractive for international students; (iii) short-term courses can increase an international dimension as, inter alia, they offer the opportunity to study abroad at home (e.g. distance learning); (iv) team-based learning forms the basis for entrepreneurship courses with integration of learning through experience and social interaction, which is why those courses foster intercultural exchange, both personally and professionally, among domestic and international students; (v) short-term entrepreneurship courses can foster internationalisation by collaborating with international partner institutions of higher education.

According to Cumming and Zhan [8] several studies have shown that common pedagogical approaches in international business education could directly apply to international entrepreneurship education. In this context authors [8, p. 181] highlight the following approaches that academics should follow in order to encourage international entrepreneurship education: (i) bringing international entrepreneurship research into the classroom; (ii) understanding the (cultural) context from which students in their classes come, with the aim to better utilize student attributes and convey messages to students in ways that they best understand; (iii) encouraging curriculum development that provides tools for understanding the roles of culture, law, economics, migration, behavioural biases, trade, and opportunities in different parts of the world; (iv) encouraging students to learn from each other's international entrepreneurship experiences.

\subsubsection{Developing intercultural and entrepreneurship competences}

Strengthening intercultural competence and attitudes through authentic cultural interactions and (online) collaborative activities with peers from other countries adds a new dimension to the entrepreneurship education model [7]. In this context, basic connections between entrepreneurship and intercultural competence should be highlighted.

Entrepreneurial thinking is relevant for all students and is considered one of the key competencies needed for the 21st century [9]. Entrepreneurship is both an individual and collective capacity for creative thinking about how to do things in new ways and develop new business ideas, as well as for mobilising others and getting them on board with your idea, understanding how to put a plan into action and use finances wisely, etc. [10]. Entrepreneurship is defined by the European Commission [10, p. 13] as a competence for life and "the capacity to act upon opportunities and ideas to create value for others. [That] value created can be social, cultural, or financial." From an intercultural perspective, Deardorff [11] defines it as the ability to interpret the world from a different point of view and show perseverance and patience in interactions with different cultures. Having respect for other cultures and viewing difference with genuine curiosity can create learning opportunities within intercultural attitudes between members of different cultures. 
With the aim to address enterprising and at the same time supporting skills identified by employers as most crucial, the focus of (formal) curriculum and competence development should be inter alia placed on intercultural awareness and intercultural learning, critical thinking, communication skills, empathy, creative problem-solving, resourcefulness, managing complexity, leadership skills, teamwork, coaching, mentoring, lobbying, and negotiating, etc. [10]. Thus, the entrepreneurship and intercultural competence can also be developed via internationalised learning outcomes with purposeful inclusion of international, intercultural, as well as entrepreneurial dimensions in learning outcomes.

The previously presented theoretical bases on intercultural learning and teaching in connection with entrepreneurship education with the aim to develop entrepreneurship and intercultural competences among future graduates form a starting point for further empirical study among Slovenian academics teaching business, IT, and services disciplines.

\section{Method}

\subsection{Research question}

Based on the previously represented theoretical background the following independent variables were identified as approaches to international entrepreneurship education that can stimulate the inclusion of intercultural and entrepreneurial elements in pedagogical activities: i) teaching international students, ii) providing distance learning with foreign institutions, iii) academics' inclusion in training courses, and iv) academics' international mobility. Besides, different pedagogical aspects were singled out that relate to the development of intercultural and entrepreneurship competences according to the theoretical bases - the latter were determined as dependent variables and are presented in chapter 3 (see: statements: $\mathrm{a}-\mathrm{i}$ ).

A research question was designed that covered the intercultural and entrepreneurial dimensions of international entrepreneurship education in the context of higher education teaching and learning activities: What is the relationship between the identified encouragers of international entrepreneurship education (see variables: $i-i v$ ) and the identified intercultural and entrepreneurial aspects of pedagogical work (see statements: $a-i)$ ?

\subsection{Data collection}

The data collection of the quantitative empirical research was based on an online questionnaire mainly using a 5-point Likert scale and covering basic steps within constructively aligned internationalised curriculum (for details see: [12]). The initial questionnaire was tested on a sample of 29 Slovenian academics familiar with the concept of internationalisation at home. The questionnaire results were sensibly transformed with the aid of univariate statistics. The survey was started at the end of 2019 and was completed after one reminder at the beginning of 2020 .

With the aim of finding appropriate answers to the research questions, the online questionnaire's advantages were much more pronounced than its disadvantages. This type of data collection is faster, as well as processing and editing the database, without the need to enter data from the questionnaire. There are also practically no survey costs.

\subsection{Population and sample}

381 Slovenian academics teaching in business, IT, and services disciplines, completed the questionnaire. The link to the online questionnaire was sent to all academic staff from the 
researched ISCED groups working at Slovenian universities and private higher education institutions.

The entire sample consisted of 1,367 respondents (teaching in different ISCED groups), of whom a subsample of 381 academics, teaching targeting disciplines, was selected. A representative demographic sample was covered in the questionnaire with slightly less than $20 \%$ of the entire Slovenian academic population (AAPOR RR3; [13]). The percentage of targeting ISCED groups covering business, IT, and services disciplines, cannot be calculated since the national Statistical Office of Republic of Slovenia does not collect the data in question at national level in such detail or according to individual ISCED group.

This percentage is estimated as a solid result for an online questionnaire in an age of declining response rates. Besides, in accordance with some researchers, even data acquired with a lower response rate can still provide accurate measurements [14].

\subsection{Data analysis}

The data was analysed with SPSS software (version 23), and the analysis was mostly based on comparing the calculated univariate and bivariate statistics, using a t-test.

\section{Results}

The respondents ranked statements and expressed their perceptions regarding following dependent variables in the context of developing intercultural and entrepreneurship competences:

a) Encouraging students to learn together in internationally mixed teams, including virtual forms of group work

b)Encouraging students from different cultural backgrounds to share (business, IT, and services related) examples from their own country

c)Including guest lecturers from (business, IT, and services related) international environment in the study process

d) Encouraging students to gain experience abroad according to their academic discipline

e)Encouraging students' ability to critically evaluate cultural and national influences on the (business, IT, and services related) academic discipline

f) Supporting students in developing soft skills like tolerance, adaptability, critical thinking, creativity etc.

g) Active involvement of students in international projects in the field

h) International or intercultural aspects are clearly expressed in learning outcomes

i) The development of soft skills is clearly expressed in learning outcomes

The results in Table 1 show statistically significant differences in the responses to the above presented dependent variables (see: statements a-i) regardless of: i) whether academics from business, IT, and services disciplines used to teach international students or not in the last 5 years, ii) whether or not they provide any kind of distance learning with institutions from abroad in which students are actively involved, iii) whether or not academics were included in training courses on how to include these dimensions in study process, and iv) whether academics have (not) been included in international mobility as part of their pedagogical work. Respondents who teach (also) international students attribute statistically significantly greater importance to: a) students' learning in internationally mixed teams, b) sharing examples from different cultural and national background, c) inclusion of guest lecturers from international environment in the study process, as well as to $g)$ students' active involvement in international projects $(p=0.000)$ in comparison to academics that have not taught international students in the last five years. 
Table 1. Academics' perceptions on selected dependent variables.

\begin{tabular}{|c|c|c|c|c|c|c|c|c|c|c|}
\hline \multicolumn{2}{|c|}{ Independent Variables } & $\mathbf{a}$ & b & c & d & e & f & g & $\mathbf{h}$ & $\mathbf{i}$ \\
\hline \multirow{3}{*}{ 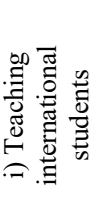 } & Yes & 4.07 & 4.28 & 3.75 & 4.00 & 3.95 & 4.20 & 3.56 & 3.37 & 3.76 \\
\hline & No & 3.39 & 3.62 & 2.96 & 3.71 & 3.84 & 4.18 & 2.74 & 3.25 & 3.68 \\
\hline & Sig. of mean dif. & 0.000 & 0.000 & 0.000 & 0.058 & 0.406 & 0.882 & 0.000 & 0.456 & 0.566 \\
\hline \multirow{3}{*}{ 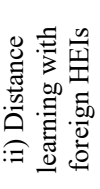 } & Yes & 4.34 & 4.43 & 4.18 & 4.27 & 4.20 & 4.42 & 3.91 & 3.68 & 3.91 \\
\hline & No & 3.63 & 3.94 & 3.13 & 3.70 & 3.76 & 4.05 & 2.95 & 3.14 & 3.66 \\
\hline & Sig. of mean dif. & 0.000 & 0.000 & 0.000 & 0.000 & 0.001 & 0.002 & 0.000 & 0.000 & 0.047 \\
\hline \multirow{3}{*}{ 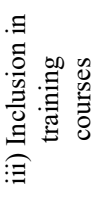 } & Yes & 4.26 & 4.35 & 3.90 & 4.13 & 4.20 & 4.45 & 3.61 & 3.82 & 3.97 \\
\hline & No & 3.68 & 3.99 & 3.32 & 3.78 & 3.74 & 4.02 & 3.23 & 2.99 & 3.58 \\
\hline & Sig. of mean dif. & 0.000 & 0.008 & 0.000 & 0.010 & 0.000 & 0.000 & 0.030 & 0.000 & 0.002 \\
\hline \multirow{3}{*}{ 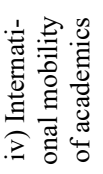 } & Yes & 4.06 & 4.28 & 3.79 & 4.08 & 4.03 & 4.23 & 3.48 & 3.42 & 3.86 \\
\hline & No & 3.58 & 3.84 & 3.01 & 3.55 & 3.69 & 4.10 & 3.17 & 3.15 & 3.48 \\
\hline & Sig. of mean dif. & 0.002 & 0.002 & 0.000 & 0.000 & 0.011 & 0.278 & 0.137 & 0.089 & 0.003 \\
\hline
\end{tabular}

Statistically significant at the level of 0.05 (if $p$ value is lower than 0.05 ).

The difference in means is particularly large when including guest lectures (0.79) and in case of active inclusion of students in international projects $(0.82)$, which means that in the latter cases the differences between the two groups of academics (those that have taught international students and those that have not taught them) are the most significant.

When considering a pedagogical approach where academics from business, IT, and services disciplines implement distance learning with institutions from abroad, in all the presented statements (see: a-i) respondents more often include international and intercultural elements in teaching and learning activities that also support the development of entrepreneurship competence (the differences are statistically significant at the level $\mathrm{p}=$ 0.000 or $\mathrm{p}<0.05)$. As in the previous independent variable the difference in means is the most significant for guest lectures from international environment (1.05), as well as in students' active inclusion in international projects (0.96).

The same applies for academics' involvement in training courses on the inclusion of international and intercultural dimensions in study processes, wherein academics that were trained statistically significantly more often include those kinds of approaches in learningteaching activities that contribute to the development of intercultural, as well as entrepreneurship competence $(p=0.000$ or $p<0.05$ ). The difference in means has the largest distance when taking into account internationalised learning outcomes (0.83), meaning that those, that were included in trainings significantly more strongly include international or intercultural dimensions in learning outcomes of business, IT, and services courses or modules.

Statistically significant differences must also be highlighted between internationally mobile and nonmobile respondents $(\mathrm{p}=0.000)$. Internationally mobile academics statistically significantly more frequently implement or attach greater importance to: a) students' learning in internationally mixed teams, b) sharing students' examples from 
different countries and cultures, c) inclusion of international guest lecturers, d) having students gain experience abroad according to their discipline, e) development of students' ability to critically evaluate cultural and national influences on considered courses/modules, as well as i) the development of soft skills in learning outcomes (see: Table 1). The difference in means is the most significant for guest lecturers from international environment (0.78).

\section{Discussion}

Developing intercultural and entrepreneurial skills has several benefits for future graduates. This process equips them for the real global, intercultural world imbued with its various uncertainties, complexities, diversities, and opportunities in jobs and everyday life. Education on internationalisation, entrepreneurship, and in this context international entrepreneurship is an important topic, to which academics and higher education institutions have devoted more and more attention in recent years.

In this paper, various aspects of developing intercultural and entrepreneurship competence were presented. These are all in their own way affected by an array of independent variables that influence their inclusion in higher education. The parallels can be highlighted using Matsekh-Ukrayinskyy et al. [2], who point out that special attention should be paid to structural questions regarding the educational design of courses in order to promote entrepreneurship education in the internationalisation context. The need to provide an equally authentic international learning experience, which brings students' cultural sensitivity to the fore, is crucial, this is why the latter should be explicitly addressed in taught programmes [7]. An important issue is devoted to the development of communicative competence of future graduates, which is highlighted by various authors $[15,16]$. Besides, explicitly addressing intercultural skills and attitudes through authentic cultural interactions with peers from different cultural backgrounds adds a new dimension to the entrepreneurship education model.

According to the research question, findings of quantitative research conducted in 2019 and 2020 among Slovenian academics from business, IT, and services disciplines, have shown that academics that include distance learning in their pedagogical approaches with higher education institutions from abroad (in which students are actively included), as well as academics that were included in training courses on intercultural and international aspects of higher education pedagogy, statistically significantly more often include international, intercultural, and entrepreneurial aspects in pedagogy for all the above presented dependent variables (see chapter 3: a-i). Those variables include students' learning in internationally mixed teams, their active involvement in international projects, encouraging students to share examples regarding their disciplines within their home culture or country, to gain academic discipline's experience abroad and to critically evaluate cultural and national influences on the discipline. Inclusion of guest lecturers from the international environment in the study process, as well as the development of soft skills (e.g. tolerance, adaptability, critical thinking, creativity, etc.), are also important for the intercultural and entrepreneurship competences increasement among students. For the purposeful and comprehensive development of such competences, the international, intercultural, and entrepreneurial aspects must be clearly expressed in learning outcomes. The same goes also for the development of soft skills, which must be clearly expressed in learning outcomes, too. Namely, learning outcomes serve as a starting point for designing the entire pedagogic process, including teaching-learning activities and assessment procedures; all the latter have a long-term impact - this is the development of intercultural and entrepreneurship competence, as well as other international and transversal skills and perspectives as the final result of the comprehensive and purposeful designing of the 
international entrepreneurship curriculum. Furthermore, academics that also used to teach international students, and academics that have been internationally mobile in the last 5 years statistically significantly more often include international, intercultural, as well as entrepreneurial aspects in their learning and teaching process (see the above presented dependent variables: $\mathrm{a}, \mathrm{b}$, c, and $\mathrm{g}$ for academics also teaching international students, and dependent variables $\mathrm{a}, \mathrm{b}, \mathrm{c}, \mathrm{d}$, e, and i for internationally mobile academics).

As Jones [1] showed, frequent surveys of employers have found that graduates often lack so-called soft skills, which are important for effective work. They are sometimes called employability skills and include teamworking, negotiation, and mediation, and problemsolving, along with interpersonal skills, flexibility, organization, and good communication. All the mentioned skills are in close relation to intercultural and entrepreneurship competences. According to the status quo in Slovenian higher education, in line with the presented survey, it can be claimed that encouraging academics to take training courses on international, intercultural, as well as entrepreneurship education, as well as to be internationally mobile, foster the inclusion and consequently the students' development of intercultural and entrepreneurship competences by academics who teach business, IT, and services disciplines. The same goes for independent variables: teaching international students and actively including them in distance learning with foreign higher education institutions should be purposefully and strategically planned and promoted among academics.

However, to broaden the results of the survey and to acquire their greater importance, it would be good to upgrade the study with additional independent and especially dependent variables (e.g. statements connected with assessment procedures in line with intercultural and entrepreneurship competences, the long-term impact of such teaching approaches to the development of intercultural and entrepreneurship competences, etc.), as well as with the inclusion of academics from other disciplines and other countries in the survey. An important fault of the survey is connected to the fact that the data were acquired at the end of 2019 and the beginning of 2020, this is before the Covid-19 epidemic was declared. The epidemic had a huge impact on the phenomenon of distance learning, which nowadays means a much easier way of working together with foreign countries and cultures. It is possible that in or after the time of epidemic, different results would be gleaned in the context of the curriculum's entrepreneurial, intercultural, and international dimensions at home or abroad.

Entrepreneurship education stimulates the development of innovative teaching formats with increased students' engagement, wherein international focus plays an important role for both domestic and international students. As Gibb, Haskins and Robertson [3] point out, it is not possible for an institution to be entrepreneurial without being international. Thus, a crucial component of a university's entrepreneurial strategy is internationalisation, with the focus on the overall integration of global, international and intercultural dimensions into the delivery, functions, and purpose of (entrepreneurship) education or curricula in the broadest sense of the words.

\section{References}

1. E. Jones, International Higher Education, 78 (special issues), 6-8 (2014)

2. L. Matsekh-Ukrayinskyy, H. L. Schneider, L. Simons, J. Münch, N. Hoegsdal, Journal Internationalisation of Higher Education - Policy and Practice, DUZ Academic Publishers, 3, 1-22. (2020) 
3. A. Gibb, G. Haskins, I. Robertson, Leading the entrepreneurial university: Meeting the entrepreneurial development needs of higher education institutions, in Universities in Change, 9-45 (Springer, New York, 2013)

4. M. I. Salem, International Business \& Economics Research Journal, 13(2), 289-294 (2014)

5. J. Beelen, E. Jones, Redefining Internationalisation at Home, in The European Higher Education Area: Between critical reflections and future policies, ed. A. Curaj, L. Matei, R. Pricopie, J. Salmi \& P. Scott, 59-72 (Springer, Dordrecht, 2015)

6. A. M. Smith, R. Paton, International Journal of Entrepreneurial Behaviour and Research, 17(1), 104-118 (2011). doi: http://dx.doi.org/10.1108/13552551111107534

7. A. M. J. Smith, Journal of Perspectives in Applied Academic Practice, 3(3), 15-23 (2015). doi: 10.14297/jpaap.v3i3.178

8. D. Cumming, F. Zhan, Journal of Teaching in International Business, 29(3), 181-184 (2018).

https://www.tandfonline.com/doi/full/10.1080/08975930.2018.1514817?scroll=top\&ne $\underline{\text { edAccess }=\text { true }}$

9. Council of the European Union, Official Journal of the European Union, 4 June, 1-13 (2018). https://eur-lex.europa.eu/legal-content

10. European Commission, EntreComp into Action: get inspired, make it happen, (Publications Office of the European Union, Luxembourg, 2018). https://ec.europa.eu/jrc/en

11. D. K. Deardorff, Journal of Studies in International Education, 10(3), 241-266 (2006). http://dx.doi.org/10.1177/1028315306287002

12. K. Aškerc Zadarvec, The international dimension of the curriculum in higher education study programmes, $\mathrm{PhD}$ Thesis (Faculty of Education, Ljubljana, 2021). http://pefprints.pef.uni-1j.si/6657/1/Disertacija_Askerc-Zadravec-K._KONCNAVERZ ODDAJA-PDF.pdf

13. AAPOR - American Association for Public Opinion Research, Standard Definitions: Final Dispositions of Case Codes and Outcome Rates for Surveys, 9th edition (The American Association for Public Opinion Research, Washington, 2016).

14. H. Horta, Higher Education, 65(4), 487-510 (2013). doi: https://link.springer.com/article/10.1007\%2Fs10734-012-9559-7

15. O. Luchaninova, V. Koval, H. Deforzh, L. Nakonechna, O. Golovnia, Espacios 40(41), 11 (2019)

16. V. Koval, Y. Polyezhayev, and A. Bezkhlibna, Communicative competences in enhancing of regional competitiveness in the labor market. Baltic Journal of Economic Studies 4, 105-113 (2019) 